\title{
ANALYSIS OF COURTSHIP BEHAVIOR AS A PARAMETER OF TOXICITY OF ETHYL METHANESULFONATE (EMS) IN DROSOPHILA MELANOGASTER
}

\author{
B.U. Divyashree ${ }^{1 *}$, M.S. Krishna ${ }^{2}$ and V. Vasudev ${ }^{1}$ \\ ${ }^{1}$ Department of Bioscience, University of Mysore, P.G. Centre, Hemagangothri, \\ Hassan-573 220, Karnataka, India \\ ${ }^{2}$ Department of Studies in Zoology, Manasagangothri, University of Mysore, \\ Mysore-570 006, Karnataka, India \\ *Corresponding author \\ Email: divyacrp6@gmail.com
}

\begin{abstract}
An anti-cancerous drug and a monofunctional alkylating agent, Ethyl methanesulfonate (EMS), was tested for its toxic effects by using courtship behavioral elements as the parameter in Drosophila melanogaster. EMS concentrations ranging from 0.5 to $15 \mathrm{mM}$ were employed by larval feeding technique to analyze the effect. When the different combinations of crosses were performed, the results have revealed that there were no qualitative differences between the control and treated groups. However, quantitatively, it has shown that male courtship elements such as orientation, tapping, wing vibration and licking were significantly prolonged compared to controls. Similar results were observed in case of female rejection behavior elements namely: ignoring, extruding and decamping. On par with this, even the courtship latency and copulation latency were significantly increased and contrary to these, copulation duration was significantly decreased, thus suggesting that the treated males were less vigor; treated females were less receptive on one hand and on the other lower reproductive fitness. Drastic effects of EMS on mating behavior prove that this can be utilized as a parameter for assessing the toxic effects of chemicals.
\end{abstract}

KEYWORDS: Ethyl methanesulfonate, Courtship elements, Drosophila melanogaster, Toxicity.

\section{INTRODUCTION}

EMS, an alkylating agent is able to produce point mutations and small deletions as well as chromosomal brakes; its recombinogenic activity is also known and it has been found to be mutagenic in a wide variety of genetic test systems from viruses to mammals ${ }^{1}$. Especially in D.melanogaster for the first time, Fahmy and Fahmy ${ }^{2}$ showed induction of sex linked recessive lethals by EMS. Latter, Muller-5 test, an attached-X test, the $\mathrm{X}$ or $\mathrm{Y}$ chromosome specific locus test, autosomal recessive lethal test have been extensively used to screen and detect different mutations induced by the EMS mutagen in D.melanogaster ${ }^{3-7}$. EMS is also shown to induce dominant lethals, wing spots, translocations, DNA damage (using comet assay) in D.melanogaster ${ }^{8-11}$.

As far as behavior genetics of D.melanogaster is considered, since the first descriptive studies by Sturtevant ${ }^{12}$, many behaviorists characterized several steps of stereotypical actions in males ${ }^{13,14}$. But an important milestone in the history of behavioral genetics is the paper of Benzer ${ }^{15}$, who used mutagenic and genetic manipulations to quantify a series of behaviors including courtship by using 
EMS. In this direction, very recently Vasudev et.al. ${ }^{16}$ used courtship behaviour as a parameter to understand the toxicity within a very short period of time in D.melanogaster. To further strength this hypothesis, the authors have used EMS as standard mutagen and the results of the same are discussed in this paper.

\section{MATERIALS AND METHODS}

\section{Test system}

In all experiments, OK strain of Drosophila melanogaster has been used as the material and the same as been obtained from Drosophila Stock Centre, Department of Zoology, University of Mysore, Mysore. Flies were maintained in the BOD incubator with $24 \pm 1^{\circ} \mathrm{C}$.

\section{Chemicals}

The well known monofunctional alkylating agent, Ethyl methanesulfonate (EMS: CAS No.62-50-0), was obtained from Sigma Chemical Company, USA and was used as the genotoxic agent to study the effects on courtship behavior. Other routine chemicals were from BDH chemical Ltd., Mumbai.

\section{Preparation of media}

a. Control media: Normal standard wheat cream agar food medium was used as control.

b. Chemical media: Various concentrations of EMS $(0.5,1.0,5,10$ and $15 \mathrm{mM}$ ) in food medium was prepared according to procedure of
Vasudev and Krishnamurthy ${ }^{17}$. This was distributed to food vials in equal quantity and was used as chemical media for all experiments.

c. Delcour media: This media was prepared according to the method of Delcour ${ }^{18}$.

d. Collection of eggs: The modified technique of Delcour was used to collect the same age of $\operatorname{eggs}^{17}$.

\section{Assessment of Rate of Development and Viability: \\ Eggs of the same age $( \pm 6 \mathrm{~h})$ in equal} numbers (100 eggs per bottle) were placed into normal and each bottle containing media of different concentrations of EMS $(0.5,1.0,5,10$ and $15 \mathrm{mM})$ and allowed to develop. The newly-hatched larvae were continuously fed on the above food media, i.e. larval feeding method ${ }^{17}$ was used. The rate of development and viability were analyzed by using the method of Vasudev and Krishnamurthy ${ }^{19}$ after the emergence of adult flies.

\section{Isolation of virgin flies for mating:}

Adult flies emerged, the virgin females and bachelor males were isolated within three to four hours of eclosion and maintained separately in normal medium. They were aged for five days for observation of the courtship behavior.

\section{Courtship behavioral assay:}

Courtship assay was conducted during the morning hours (7-10 A.M.) every day in a room with a temperature of $24 \pm 1{ }^{\circ} \mathrm{C}$ 
under normal laboratory light condition. A single virgin female was introduced into Elens-Wattiaux mating chamber without etherizing them, using an aspirator. A bachelor male was added to it and allowed to acclimatize to the chamber for $30 \mathrm{sec}$. The details of courtship behavior were directly observed through hand lens of $10 \mathrm{x}$ magnification. Depending upon the experimental protocols mentioned below, flies were introduced into the observation chamber. Courtship activities such as orientation, tapping, wing vibration and licking which are male-specific activities and ignoring, extruding and decamping which are female-specific activities and copulation duration were recorded separately in the control and treated groups. From these data, courtship latency and copulation latency were analyzed and tabulated. Continuous observations were made for 30 minutes, then if there had been no copulation, that was considered as unmated and that pair was replaced by fresh pair. Mating chamber was washed every time after each observation to remove sex pheromones of previous couples, if any.

\section{Experimental protocols:}

Control: Untreated male and female flies were released into mating chambers to observe for their mating behavior.

Female treated: Female treated with $0.5,1.0,5,10$ or $15 \mathrm{mM}$ of EMS was released with control male into the mating chamber.

Male treated: Male treated with 0.5 ,
$1.0,5,10$ or $15 \mathrm{mM}$ of EMS was released with control female into the mating chamber.

Both treated: Both male and female flies treated with $0.5,1.0,5,10$ or $15 \mathrm{mM}$ of EMS were released into the mating chamber.

Twenty five pairs were observed for each experiment and we repeated the experiments thrice. As a whole, we recorded 75 observations each for treated and control groups.

\section{Statistical analysis}

The data obtained from the individual experiments were subjected to statistical analysis to determine the significance level between the control and treatment groups. The data were expressed as Mean $\pm \mathrm{SE}$ and compared using a one-way analysis of variance (ANOVA). Comparisons among groups were analyzed according to Tukey's post hoc test using the SPSS statistical package version 23.0. Significance level was tested at $\mathrm{p}<0.05$.

\section{RESULTS AND DISCUSSION}

\section{Rate of Development and Viability:}

The results have revealed that there is dose dependent increase in rate of development and the viability is significantly reduced to $53.22 \%$ in the highest dose (15mM) tested (data not given) compared to controls $(\mathrm{p}<0.05)$.

\section{Courtship behavioral assay:}

When different combinations of crosses were performed to analyze the effect 
of EMS on courtship behaviour, qualitative data are similar in all experimental groups analyzed, but on the other hand, quantitatively, the results have revealed that there are significant differences between treated groups and control (Tables 1, 2, 3, $\mathrm{p}<0.05)$. Nonetheless, it is clear from each table that male courtship behaviors like orientation, tapping, wing vibration and licking show significant increase in a dose dependent manner compared to controls. The highest effect of EMS is noticed in the highest dose tested of all courtship elements. Tables also reveal the concordant results obtained from different types of experimental schedules. On par with this, even in female rejection elements of D.melanogaster, there is an increase in dose dependent manner compared to controls (Figs. 1, 2, 3 p <0.05). The courtship latency and copulation latency have been shown to be significantly extended in all the experimental treated groups compared to controls (Tables 1, 2, 3, p<0.05). Contrary to this, the copulation duration is significantly decreased in different treated groups than that of controls (Tables 1, 2, 3, $\mathrm{p}<0.05)$. The highest reduction of courtship duration is noticed when both males and females are treated. For example, the courtship duration in this group is $11.47 \pm 0.13 \mathrm{~min}$ compared to $19.35 \pm 0.05$ min in control (Table 3 ). These findings are suggestive of overall ailment in performance of courtship by both male and female under treatment with EMS compared to control.

Table-1. Effect of different concentrations of EMS on courtship elements of D.melanogaster when male is treated and paired with normal female

\begin{tabular}{|l|c|c|c|c|c|c|c|}
\hline $\begin{array}{l}\text { Concentrations } \\
\text { (in } \mathrm{mM} \text { ) }\end{array}$ & $\begin{array}{c}\text { Orientation } \\
\text { (in numbers) }\end{array}$ & $\begin{array}{c}\text { Tapping } \\
\text { (in numbers) }\end{array}$ & $\begin{array}{c}\text { Wing vibration } \\
\text { (in numbers) }\end{array}$ & $\begin{array}{c}\text { Licking } \\
\text { (in numbers) }\end{array}$ & $\begin{array}{c}\text { Courtship } \\
\text { latency (sec.) }\end{array}$ & $\begin{array}{c}\text { Copulation } \\
\text { latency(min.) }\end{array}$ & $\begin{array}{c}\text { Copulation } \\
\text { duration (min.) }\end{array}$ \\
\hline Control & $4.58 \pm 0.07^{\mathrm{a}}$ & $3.62 \pm 0.07^{\mathrm{a}}$ & $4.64 \pm 0.05^{\mathrm{a}}$ & $2.43 \pm 0.04^{\mathrm{a}}$ & $10.80 \pm 0.16^{\mathrm{a}}$ & $1.51 \pm 0.02^{\mathrm{a}}$ & $19.35 \pm 0.05^{\mathrm{a}}$ \\
\hline 0.5 & $5.36 \pm 0.26^{\mathrm{b}}$ & $4.43 \pm 0.32^{\mathrm{ab}}$ & $5.91 \pm 0.26^{\mathrm{b}}$ & $2.98 \pm 0.37^{\mathrm{ab}}$ & $16.28 \pm 0.42^{\mathrm{b}}$ & $2.87 \pm 0.23^{\mathrm{b}}$ & $18.37 \pm 0.11^{\mathrm{b}}$ \\
\hline 1 & $8.71 \pm 0.22^{\mathrm{c}}$ & $5.20 \pm 0.38^{\mathrm{b}}$ & $7.74 \pm 0.28^{\mathrm{c}}$ & $3.62 \pm 0.25^{\mathrm{b}}$ & $19.76 \pm 0.28^{\mathrm{c}}$ & $3.81 \pm 0.29^{\mathrm{c}}$ & $16.54 \pm 0.04^{\mathrm{c}}$ \\
\hline 5 & $13.81 \pm 0.26^{\mathrm{d}}$ & $10.78 \pm 0.26^{\mathrm{c}}$ & $12.71 \pm 0.15^{\mathrm{d}}$ & $6.30 \pm 0.28^{\mathrm{c}}$ & $23.07 \pm 0.30^{\mathrm{d}}$ & $5.58 \pm 0.28^{\mathrm{d}}$ & $15.67 \pm 0.02^{\mathrm{d}}$ \\
\hline 10 & $19.04 \pm 0.26^{\mathrm{e}}$ & $15.76 \pm 0.26^{\mathrm{d}}$ & $17.85 \pm 0.31^{\mathrm{e}}$ & $8.23 \pm 0.30^{\mathrm{d}}$ & $29.21 \pm 0.29^{\mathrm{e}}$ & $7.89 \pm 0.31^{\mathrm{e}}$ & $13.79 \pm 0.10^{\mathrm{e}}$ \\
\hline 15 & $25.93 \pm 0.27^{\mathrm{f}}$ & $19.69 \pm 0.25^{\mathrm{e}}$ & $21.23 \pm 0.20^{\mathrm{f}}$ & $14.05 \pm 0.25^{\mathrm{e}}$ & $35.77 \pm 0.25^{\mathrm{f}}$ & $10.66 \pm 0.26^{\mathrm{f}}$ & $12.79 \pm 0.03^{\mathrm{f}}$ \\
\hline
\end{tabular}

Note: Data of 3 independent experiments; 25 pairs per experiment were used; Mean with SE are given. Values with the same superscripts are not significantly different $(p>0.05)$ whereas values with different superscripts are significantly different $(\mathrm{p}<0.05)$ from one another. 
Table-2. Effect of different concentrations of EMS on courtship elements of D.melanogaster when female is treated and paired with normal male

\begin{tabular}{|l|c|c|c|c|c|c|c|}
\hline $\begin{array}{l}\text { Concentrations } \\
\text { (in } \mathrm{mM} \text { ) }\end{array}$ & $\begin{array}{c}\text { Orientation } \\
\text { (in numbers) }\end{array}$ & $\begin{array}{c}\text { Tapping } \\
\text { (in numbers) }\end{array}$ & $\begin{array}{c}\text { Wing vibration } \\
\text { (in numbers) }\end{array}$ & $\begin{array}{c}\text { Licking } \\
\text { (in numbers) }\end{array}$ & $\begin{array}{c}\text { Courtship } \\
\text { latency (sec.) }\end{array}$ & $\begin{array}{c}\text { Copulation } \\
\text { latency(min.) }\end{array}$ & $\begin{array}{c}\text { Copulation } \\
\text { duration (min.) }\end{array}$ \\
\hline Control & $4.58 \pm 0.07^{\mathrm{a}}$ & $3.62 \pm 0.07^{\mathrm{a}}$ & $4.64 \pm 0.05^{\mathrm{a}}$ & $2.43 \pm 0.04^{\mathrm{a}}$ & $10.80 \pm 0.16^{\mathrm{a}}$ & $1.51 \pm 0.02^{\mathrm{a}}$ & $19.35 \pm 0.05^{\mathrm{a}}$ \\
\hline 0.5 & $6.59 \pm 0.26^{\mathrm{b}}$ & $5.49 \pm 0.27^{\mathrm{b}}$ & $6.80 \pm 0.34^{\mathrm{b}}$ & $3.69 \pm 0.32^{\mathrm{b}}$ & $14.37 \pm 0.25^{\mathrm{b}}$ & $2.86 \pm 0.04^{\mathrm{b}}$ & $18.67 \pm 0.05^{\mathrm{b}}$ \\
\hline 1 & $10.79 \pm 0.33^{\mathrm{c}}$ & $7.81 \pm 0.23^{\mathrm{c}}$ & $9.88 \pm 0.34^{\mathrm{c}}$ & $5.89 \pm 0.27^{\mathrm{c}}$ & $17.05 \pm 0.25^{\mathrm{c}}$ & $4.77 \pm 0.24^{\mathrm{c}}$ & $17.54 \pm 0.03^{\mathrm{c}}$ \\
\hline 5 & $15.93 \pm 0.27^{\mathrm{d}}$ & $12.81 \pm 0.22^{\mathrm{d}}$ & $14.86 \pm 0.25^{\mathrm{d}}$ & $7.91 \pm 0.34^{\mathrm{d}}$ & $20.91 \pm 0.38^{\mathrm{d}}$ & $6.76 \pm 0.29^{\mathrm{d}}$ & $16.62 \pm 0.07^{\mathrm{d}}$ \\
\hline 10 & $21.78 \pm 0.35^{\mathrm{e}}$ & $17.94 \pm 0.33^{\mathrm{e}}$ & $19.86 \pm 0.35^{\mathrm{e}}$ & $11.79 \pm 0.28^{\mathrm{e}}$ & $26.61 \pm 0.29^{\mathrm{e}}$ & $8.10 \pm 0.08^{\mathrm{e}}$ & $14.65 \pm 0.11^{\mathrm{e}}$ \\
\hline 15 & $27.65 \pm 0.25^{\mathrm{f}}$ & $22.01 \pm 0.25^{\mathrm{f}}$ & $23.82 \pm 0.27^{\mathrm{f}}$ & $15.82 \pm 0.15^{\mathrm{f}}$ & $32.72 \pm 0.20^{\mathrm{f}}$ & $12.78 \pm 0.28^{\mathrm{f}}$ & $13.55 \pm 0.04^{\mathrm{f}}$ \\
\hline
\end{tabular}

Note: Data of 3 independent experiments; 25 pairs per experiment were used; Mean with SE are given. Values with the same superscripts are not significantly different $(p>0.05)$ whereas values with different superscripts are significantly different $(\mathrm{p}<0.05)$ from one another

Table-3. Effect of different concentrations of EMS on courtship elements of D.melanogaster when treated male and female is paired

\begin{tabular}{|l|c|c|c|c|c|c|c|}
\hline $\begin{array}{l}\text { Concentrations } \\
\text { (in } \mathrm{mM} \text { ) }\end{array}$ & $\begin{array}{c}\text { Orientation } \\
\text { (in numbers) }\end{array}$ & $\begin{array}{c}\text { Tapping } \\
\text { (in numbers) }\end{array}$ & $\begin{array}{c}\text { Wing vibration } \\
\text { (in numbers) }\end{array}$ & $\begin{array}{c}\text { Licking } \\
\text { (in numbers) }\end{array}$ & $\begin{array}{c}\text { Courtship } \\
\text { latency (sec.) }\end{array}$ & $\begin{array}{c}\text { Copulation } \\
\text { latency(min.) }\end{array}$ & $\begin{array}{c}\text { Copulation } \\
\text { duration (min.) }\end{array}$ \\
\hline Control & $4.58 \pm 0.07^{\mathrm{a}}$ & $3.62 \pm 0.07^{\mathrm{a}}$ & $4.64 \pm 0.05^{\mathrm{a}}$ & $2.43 \pm 0.04^{\mathrm{a}}$ & $10.80 \pm 0.16^{\mathrm{a}}$ & $1.51 \pm 0.02^{\mathrm{a}}$ & $19.35 \pm 0.05^{\mathrm{a}}$ \\
\hline 0.5 & $8.70 \pm 0.26^{\mathrm{b}}$ & $6.79 \pm 0.37^{\mathrm{b}}$ & $7.63 \pm 0.40^{\mathrm{b}}$ & $4.71 \pm 0.26^{\mathrm{b}}$ & $18.86 \pm 0.29^{\mathrm{b}}$ & $3.70 \pm 0.28^{\mathrm{b}}$ & $17.63 \pm 0.11^{\mathrm{b}}$ \\
\hline 1 & $11.85 \pm 0.38^{\mathrm{c}}$ & $9.24 \pm 0.26^{\mathrm{c}}$ & $11.76 \pm 0.36^{\mathrm{c}}$ & $7.18 \pm 0.19^{\mathrm{c}}$ & $21.75 \pm 0.44^{\mathrm{c}}$ & $5.03 \pm 0.31^{\mathrm{c}}$ & $15.54 \pm 0.13^{\mathrm{c}}$ \\
\hline 5 & $19.80 \pm 0.39^{\mathrm{d}}$ & $15.81 \pm 0.27^{\mathrm{d}}$ & $18.77 \pm 0.16^{\mathrm{d}}$ & $10.06 \pm 0.10^{\mathrm{d}}$ & $25.34 \pm 0.21^{\mathrm{d}}$ & $7.87 \pm 0.24^{\mathrm{d}}$ & $14.59 \pm 0.08^{\mathrm{d}}$ \\
\hline 10 & $25.85 \pm 0.44^{\mathrm{e}}$ & $19.41 \pm 0.26^{\mathrm{e}}$ & $23.55 \pm 0.26^{\mathrm{e}}$ & $15.95 \pm 0.28^{\mathrm{e}}$ & $31.70 \pm 0.22^{\mathrm{e}}$ & $9.79 \pm 0.24^{\mathrm{e}}$ & $12.67 \pm 0.09^{\mathrm{e}}$ \\
\hline 15 & $30.77 \pm 0.25^{\mathrm{f}}$ & $24.89 \pm 0.36^{\mathrm{f}}$ & $26.41 \pm 0.28^{\mathrm{f}}$ & $18.84 \pm 0.25^{\mathrm{f}}$ & $38.09 \pm 0.26^{\mathrm{f}}$ & $13.83 \pm 0.24^{\mathrm{f}}$ & $11.47 \pm 0.13^{\mathrm{f}}$ \\
\hline
\end{tabular}

Note: Data of 3 independent experiments; 25 pairs per experiment were used; Mean with SE are given. Values with the same superscripts are not significantly different $(p>0.05)$ whereas values with different superscripts are significantly different $(\mathrm{p}<0.05)$ from one another. 


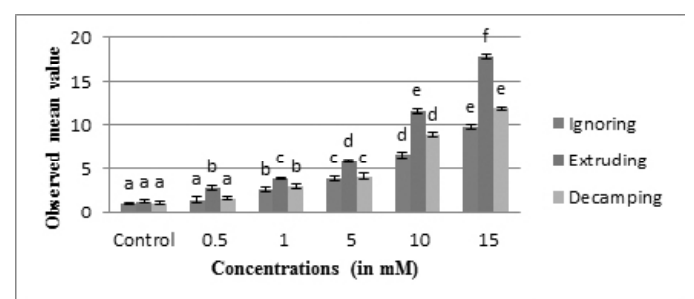

Figure-1. Female rejection courtship elements of D.melanogaster after EMS treated male is paired with a normal female.

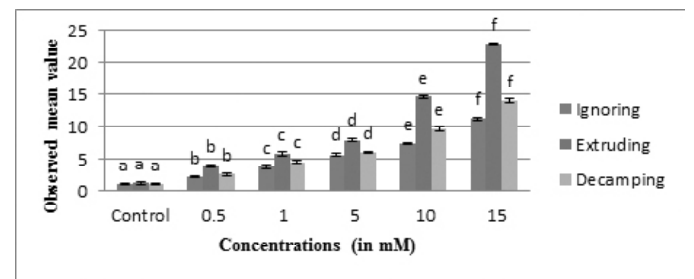

Figure-2. Female rejection courtship elements of D.melanogaster after EMS treated female is paired with a normal male.

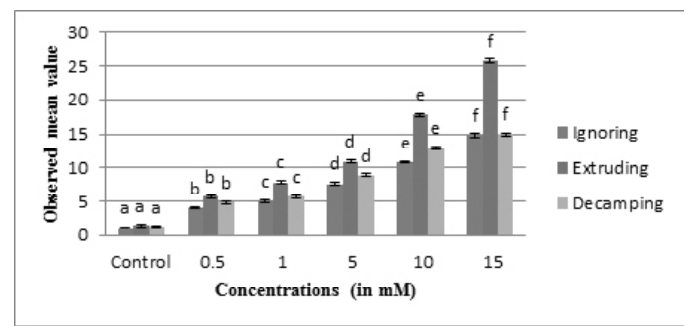

Figure-3. Female rejection courtship elements of D.melanogaster after EMS treated male and female is paired.

William E. Castle was the first person to use Drosophila for a genetic study in the laboratory at Harvard University in $1901^{20}$. Subsequently he and his students began to study simple behaviors which included phototaxis, mechanosensory, olfactory response and not the least courtship behavior but until the work of Sturtevant ${ }^{12}$, Drosophila has not been recognized as a model organism for courtship behaviour. When the scientists started to use courtship behaviour of Drosophila, it was basically for understanding isolation mechanism, sexual selection, intraspecific variations and interspecific behavior ${ }^{21}$. A new line of research was started with publication of Benzer ${ }^{15}$ who fed EMS to Drosophila male flies to screen their offspring's for behavioral phenotypes, then used genetic crosses to isolate genes responsible for their altered behaviors. Being best model organism for genetic studies with many advantages, time and again new parameters are being introduced. One such parameter is the introduction of mating behaviour to understand toxicity within a short period of time $^{16}$. In the present studies, to strengthen the said hypothesis, a standard monofunctional ethylating agent - Ethyl methanesulfonate (EMS) has been used. The results have revealed that qualitative data of courtship behavior of present study such as orientation, tapping, wing vibration, licking, and mounting are similar to that described by Bostock and Manning ${ }^{14}$ and Spieth $^{22}$. There is no variation between treated groups and controls with regard to courtship behavior and thus it is opined that EMS has not affected the courtship elements qualitatively.

Quantitatively, the behavioral attributes during courtship like orientation, tapping, wing vibration, licking and copulation attempts have significantly increased in different experimental regime, thus exhibiting the sign of EMS toxicity in 
D.melanogaster (Tables 1, 2, 3, p<0.05). Toxicity of EMS has also been demonstrated by Yang et.al. ${ }^{23}$ by employing EMS on the following nine quantitative traits such as developmental trait, viability, longevity, metabolite rate, mortality, body weight and abdominal and sternopleural bristle numbers of D.melanogaster. Similarly in the present experiment, rate of development and viability which are the best parameters of toxicity as proposed by Lunning ${ }^{24}$ were significantly affected by EMS in dose dependent manner (data not given). Further different chemicals agents have been tested by Nazari and Hegde ${ }^{25}$, Nazari ${ }^{26}$, Roy and Ghosh $^{27}$ and Vasudev et.al. ${ }^{16}$ and they showed that these chemicals do alter the courtship behaviour of D.melanogaster

To understand the extent of differences among fitness characters such as courtship latency and copulation latency, the pooled data of the three tables were looked into. A male with high vigor reacts quickly in the presence of female while a male with less vigor, reacts slowly ${ }^{28}$. On the other hand, it also reflects the receptivity of females. In the present study, significantly longer courtship and copulation latency was noticed in experimental treated groups (Tables 1, 2, 3, p<0.05) indicating that males require longer duration to attract females. It is also known that Drosophila males with high vigor have to perform the same courtship act many times to a non-receptive female than to a receptive female and vice versa. It is clear from the results that the treated males could not maintain high vigor and treated females are less receptive. According to Guruprasad et.al. ${ }^{29}$, a longer duration permits transfer of more sperms by males to the female genital organ. It also enhances the fitness of the females, because the sperm received by a female can fertilize more eggs. In the present study, in the treated groups, the copulation duration is significantly less compare to control (Tables $1,2,3, \mathrm{p}<0.05)$. Further, from these tables it is also clear that treated females are much more affected interms of individual acts compared to treated males.

The non-receptive female escapes from the courtship activities of male by ignoring, extruding and decamping. If she decides to accept the male, she slows down, ceases rejection behaviors and opens her vaginal plate for copulation ${ }^{30}$. After successful copulation, mated females become temporarily sexually unreceptive to further copulatory attempts, increasing their rate of egg-laying ${ }^{31}$. However, the present results revealed that ignoring, extruding and decamping behaviors of females shows significantly increased in different treated groups of EMS compared to controls (Figs $1,2,3, \mathrm{p}<0.05)$. Nonetheless, these elements are more pronounced when female is treated (Fig-2) compared to treated male (Fig-1). However, it is significantly expressed when both male and female treated (Fig-3, $\mathrm{p}<0.05)$.

When the data are pooled together it is interesting to note the toxicity in terms of increased rate of development, less viability, less fecundity, reduced size of 
imago on one hand and effect on courtship behavior leading to less vigor and less receptivity on the other. All these factors are coinciding, resulting in the effect of EMS on fitness of D. melanogaster and thus it can be opined without doubt that courtship behavior can be used as a parameter of toxicity in D.melanogaster.

\section{CONCLUSION}

In conclusion, it can be said that EMS is harmful to D.melanogaster with a spectrum of adverse effects on different courtship activities, thus characterizing toxic effects of EMS. Furthermore, especially increased courtship and copulation latencies and reduced copulation duration are the indicators of reduced fitness due to toxicity of EMS, similar to that of reduced viability. This may lead to new direction of research in understanding toxicity of EMS in particular and other agents in general, on other model organisms and humans.

\section{REFERENCES}

1. Sega, G., 1984. A review of the genetic effects of ethyl methanesulfonate. Mutation research, 134: 113-142.

2. Fahmy, O. \& M. Fahmy, 1957. Mutagenic Response to the Alkyl-Methanesulphonates During Spermatogenesis in Drosophila Melanogaster. Nature, 180:31-34.

3. Alderson, T., 1965. Chemically Induced Delayed Germinal Mutation in Drosophila. Nature. 207: 164-167.

4. Jenkins, J.B., 1967. The induction of mosaic and complete dumpy mutants in Drosophila melanogaster with Ethyl methanesulfonate. Mutat Res., 4: 90-2.
5. Lee, W.R., G.A. Sega \& J.B. Bishop, 1970. Chemically induced mutations observed as mosaics in Drosophila melanogaster. Mutat Res., 9: 323-36.

6. Bishop, J.B. \& W.R. Lee, 1973. Chromosome breakage in Drosophila melanogaster induced by a monofunctional alkylating agent (EMS). Mutat Res., 21: 327-33.

7. Vogel, E. \& A.T. Natarajan, 1979. The relation between reaction kinetics and mutagenic action of mono-functional alkylating agents in higher eukaryotic systems: I. Recessive lethal mutations and translocations in Drosophila. Mutat Res Fund Mol Mech Mutagen., 62: 51-100.

8. Graf, U., H. Frei, A. Kägi, A.J. Katz \& F.E. Würgler, 1989. Thirty compounds tested in the Drosophila wing spot test. Mutat Res., 222: 359-73.

9. Würgler, F.E., 1980. Mutagenicity testing with Drosophila. Arch Toxicol., 46: 77-87.

10. Siddique, H.R., D.K. Chowdhuri, D.K. Saxena \& A. Dhawan, 2005. Validation of Drosophila melanogaster as an in vivo model for genotoxicity assessment using modified alkaline Comet assay. Mutagenesis, 20: 28590.

11. Furlanetto, M.P., M. Sinigaglia, V.S. Amaral, R.R. Dihl \& H.H. de Andrade, 2007. Effect of vanillin on toxicant-induced lethality in the Drosophila melanogaster DNA repair test. Environ Mol Mutagen., 48: 67-70.

12. Sturtevant, A.H., 1915. Experiments on sex recognition and the problems of sexual selection in Drosophila. Anim. Behav., 5: 351-366.

13. Spieth, H.T., 1952. Mating within the genus Drosophila (Diptera). Bull. Am. Museum Nat. Hist., 99: 395-474.

14. Bastock, M. \& A. Manning, 1955. The courtship of Drosophila melanogaster Behaviour, 8: 85-111.

15. Benzer, S., 1967. Behavioral mutants Of Drosophila isolated by countercurrent distribution. Proc Natl Acad Sci., U S A., 58: 
1112-1119.

16. Vasudev, V., H.P. Gurushankara, P. Vishwaprakash Mahadimane, D. Khalandar \& B.R. Shamprasad, 2013. Effects of fungicide Dithane M-45 in Drosophila melanogaster on courtship behavior. Dros Inf Serv., 96: 94-98.

17. Vasudev, V. \& N.B. Krishnamurthy, 1979. Toxicity of Dithane M-45 on Drosophila melanogaster. Experientia, 35: 528-529.

18. Delcour, J., 1969. A rapid and efficient method of egg collecting. Dros Inf Serv. 44: 133-134.

19. Vasudev, V. \& N.B. Krishnamurthy, 1982. Effect of Dithane M-45 on the rate of development, viability, morphology, and fecundity in Drosophila melanogaster. Mysore Univ. Sec. B. Sci., 29: 79-86.

20. Allen, G.E., 1975. The introduction of Drosophila into the study of heredity and evolution: 1900-1910. Isis, 66: 322-33.

21. Spieth, H.T., 1968. Evolutionary implications of sexual behavior in Drosophila. Evolutionary Biology. Springer, Boston, MA. pp. 157-193.

22. Spieth, H.T., 1974. Courtship behavior in Drosophila. Annu. Rev. Entomol. 19: 385405.

23. Yang, X., D.M. Li, W. Chen, T. Xu, 2001. Human homologue of Drosophila lats, LATS1, negatively regulate growth by inducing $\mathrm{G}(2) / \mathrm{M}$ arrest or apoptosis. Oncogene, 20: 6516-23.
24. Lüning, K.G., 1966. Drosophila tests in pharmacology. Nature., 209: 84-86.

25. Nazari, M. \& S.N. Hegde, 2006. Effect of fluoxetine on the courtship latency, mating latency and copulation duration of Drosophila melanogaster. J. Postgrad Med Inst., 20: 58-63.

26. Nazari, M., 2011. Effect of fluoxetine on the sexual behaviour of Drosophila melanogaster. J. Postgrad Med Inst., 25: 298-303.

27. Roy, S.S. \& S. Ghosh, 2019. Effects of Fruit Ripening Retardant Alar (Daminozide) on Behaviour of Drosophila melanogaster. Proc Zool Soc., 73: 296-301.

28. Markow, T.A., M. Quaid \& S. Kerr, 1978. Male mating experience and competitive courtship success in Drosophila melanogaster. Nature., 276: 821-822.

29. Guruprasad, B.R., S.N. Hegde \& M.S. Krishna, 2008. Positive correlation between male size and remating success in few populations of D.bipectinata. Zool Stud., 47: 75-83.

30. Villella, A. \& J.C. Hall, 2008. Neurogenetics of courtship and mating in Drosophila. Adv Genet., 62: 67-184.

31. Kubli, E., 2003. Sex-peptides: seminal peptides of the Drosophila male. Cell Mol Life Sci., 60: 1689-704. 
